Check for updates

Cite this: RSC Adv., 2017, 7, 51993

Received 12th August 2017

Accepted 13th October 2017

DOI: $10.1039 / c 7 r a 08937 f$

rsc.li/rsc-advances

\section{Synthesis of core-shell structured magnetic mesoporous silica microspheres with accessible carboxyl functionalized surfaces and radially oriented large mesopores as adsorbents for the removal of heavy metal ions $\dagger$}

\author{
Shushan Hou, (D) Xiaoju Li, Hongli Wang, Minggang Wang, Ying Zhang, Yue Chi* \\ and Zhankui Zhao*
}

In this work, we report the fabrication of novel multifunctional microspheres which are composed of ordered mesoporous silica shells with accessible carboxyl functionalized surfaces and radially oriented large mesopores, and nonporous silica-coated magnetite cores $\left(\mathrm{Fe}_{3} \mathrm{O}_{4}\right)$, aiming to remove heavy metal ions from aqueous media. The well-designed multifunctional microspheres were thoroughly characterized with transmission electron microscopy, scanning electron microscopy, infrared spectroscopy, $\mathrm{N}_{2}$ adsorption-desorption, $\mathrm{X}$-ray diffraction as well as magnetization measurements. The as-prepared microspheres possess unique properties including stably grafted and accessible carboxyl groups, highly open mesopores (11.03 nm), high magnetization (34.5 emu g ${ }^{-1}$ ), and large BET surface areas $\left(165 \mathrm{~m}^{2} \mathrm{~g}^{-1}\right)$, and as a result, the as-prepared microspheres exhibit an enhanced performance for the removal of $\mathrm{Cd}(॥), \mathrm{Cu}(॥)$, and $\mathrm{Pb}(॥)$ from wastewater, with a high adsorption capacity, a rapid adsorption rate, and an easy magnetically separable process.

\section{Introduction}

Rapid industrialization has generated heavy metal contamination and intensified the presence of heavy metals in water. Accumulated heavy metals do great harm to the environment and to human health even at quite low concentrations. Many methods have been applied for treating heavy metals in wastewater, such as chemical precipitation, ${ }^{1}$ solvent extraction, ${ }^{2}$ ionexchange, $^{3}$ adsorption $^{4-6}$ and nanofiltration. ${ }^{7}$ Among these methods, adsorption has received more attention due to its high efficiency, simplicity, and low cost. ${ }^{8-10}$

Owing to its excellent features (such as high surface area, large pore volume, regular and tunable pore size, and chemical stability), mesoporous silica has been extensively employed as an adsorbent to remove different heavy metal ions. ${ }^{11,12}$ Up to now, although mesoporous silica adsorbents have been developed, their practical applications in treating wastewater are still limited by inconvenient recycling. Recently, significant efforts have been devoted to the

College of Material Science and Engineering, Key Laboratory of Advanced Structural Materials, Ministry of Education, Changchun University of Technology, Changchun, 130012, China. E-mail: yuechi@ccut.edu.cn; zhaozk@ccut.edu.cn; Fax: +86 431 85716644; Tel: +8643185716644

$\dagger$ Electronic supplementary information (ESI) available. See DOI: 10.1039/c7ra08937f application of core-shell structured magnetic mesoporous silica in the adsorption of heavy metals due to convenient magnetic separation and recycling processes. To get enhanced adsorption performance, a further step beyond the preparation of mesoporous silica is the construction of coreshell structured magnetic mesoporous silica by combining the advantages of mesoporosity with the magnetic properties, which could lead to excellent candidates for treating heavy metals in wastewater. ${ }^{\mathbf{1 3 , 1 4}}$

On the other hand, functional groups such as amino or thiol groups can be immobilized on mesoporous silica by a grafting process to fine-tune the interactions with heavy metal ions, through which the adsorption performance can be elevated to the next level. ${ }^{15,16}$ However, the uncontrollable post-synthesis grafting process may give rise to pore plugging, which is disadvantageous to the adsorption capacity and kinetics. The construction of mesoporous silica integrating functionalized surfaces and accessible mesopores has long been one of the most attractive targets for various groups, aiming to make the surface active for the immobilization of heavy metal ions and to improve the efficiency of mesopore usage and rapid mass transfer. ${ }^{17,18}$

On the basis of comprehensive considerations, we prepared core-shell structured magnetic mesoporous silica microspheres with a carboxyl functionalized surface and radially oriented large mesopores, which combined the advantages of good 
magnetic separability, suitable surface properties and a mesoporous structure. ${ }^{19}$ The radially oriented large mesopores on the magnetic microspheres are sufficiently large avoiding the plugging caused by surface modification, so that the carboxyl groups immobilized inside the mesopores could maintain accessible formation. The obtained core-shell structured magnetic mesoporous silica microspheres showed fast adsorption speed, high capacity and good recycling stability for trapping $\mathrm{Cd}(\mathrm{II}), \mathrm{Cu}$ (II), and $\mathrm{Pb}$ (II) from wastewater.

\section{Experimental}

\subsection{Chemicals}

Cetyltrimethylammonium bromide (CTAB) and (3-aminopropyl)trimethoxysilane (APTMS) were purchased from Aladdin Industrial Corporation. Other chemicals were purchased from Beijing Chemical Corp. All chemicals were directly used as received without any further purification. Deionized water was used in all experiments.

\subsection{Methods}

2.2.1 Synthesis of the $\mathrm{Fe}_{3} \mathrm{O}_{4} @ \mathrm{SiO}_{2} @ \mathrm{mSiO}_{2}$ microspheres. The $\mathrm{Fe}_{3} \mathrm{O}_{4}$ and $\mathrm{Fe}_{3} \mathrm{O}_{4} @ \mathrm{SiO}_{2}$ microspheres were prepared as previously described. ${ }^{20}$ Briefly, $0.6 \mathrm{~g}$ of CTAB and $0.2 \mathrm{~g}$ of triethanolamine (TEA) were dissolved in deionized water $(60 \mathrm{~mL})$ by vigorous mechanical stirring to obtain a clear dispersion. Afterwards, $0.15 \mathrm{~g}$ of the $\mathrm{Fe}_{3} \mathrm{O}_{4} @ \mathrm{SiO}_{2}$ microspheres was added and treated ultrasonically for $30 \mathrm{~min}$. Into the resulting dispersion, $0.2 \mathrm{~mL}$ of tetraethyl orthosilicate (TEOS) and $0.18 \mathrm{~mL}$ of cyclohexane were added consecutively. The mixture was ultrasonicated for $15 \mathrm{~min}$ and was then mechanically stirred at $60^{\circ} \mathrm{C}$ for $12 \mathrm{~h}$. The product was collected with the help of a magnetic field, followed by washing repeatedly with deionized water and ethanol. Finally, the product was dried at $60{ }^{\circ} \mathrm{C}$ overnight, then calcined at $550{ }^{\circ} \mathrm{C}$ for $6 \mathrm{~h}$ (here, it was named $\mathrm{Fe}_{3} \mathrm{O}_{4} @ \mathrm{SiO}_{2} @ \mathrm{mSiO}_{2}$ ).

2.2.2 Synthesis of the amino functionalized $\mathrm{Fe}_{3} \mathrm{O}_{4}$ @$\mathrm{SiO}_{2} @ \mathrm{mSiO}_{2}$ microspheres. In a typical procedure, $0.1 \mathrm{~g}$ of the $\mathrm{Fe}_{3} \mathrm{O}_{4} @ \mathrm{SiO}_{2} @ \mathrm{mSiO}_{2}$ microspheres was added into the mixed solution containing $50 \mathrm{~mL}$ of toluene and $4 \mathrm{~mL}$ of APTMS, then the mixture was refluxed at $110{ }^{\circ} \mathrm{C}$ with continuous stirring for $24 \mathrm{~h}$. The product was washed with water and ethanol several times, and dried at $60{ }^{\circ} \mathrm{C}$ for $6 \mathrm{~h}$ (here, it was named $\mathrm{Fe}_{3} \mathrm{O}_{4}$ @$\mathrm{SiO}_{2} @ \mathrm{mSiO}_{2}-\mathrm{NH}_{2}$ ).

2.2.3 Synthesis of the carboxyl functionalized $\mathrm{Fe}_{3} \mathrm{O}_{4} @-$ $\mathrm{SiO}_{2} @ \mathrm{mSiO}_{2}$ microspheres. $0.1 \mathrm{~g}$ of the $\mathrm{Fe}_{3} \mathrm{O}_{4} @ \mathrm{SiO}_{2} @ \mathrm{mSiO}_{2}-$ $\mathrm{NH}_{2}$ microspheres was dispersed in a $30 \mathrm{~mL}$ glutaral solution (5 wt\%) and ultrasonicated for $1 \mathrm{~h}$. The recovered solid was washed with deionized water to remove the physically adsorbed species, and re-dispersed in $30 \mathrm{~mL}$ of a $\mathrm{H}_{2} \mathrm{O}_{2}$ solution ( $30 \mathrm{wt} \%$ ) by mechanically stirring at $40{ }^{\circ} \mathrm{C}$ for $6 \mathrm{~h}$. The product was magnetically separated, washed several times with deionized water, and dried at $60{ }^{\circ} \mathrm{C}$ for $6 \mathrm{~h}$ (here, it was named $\mathrm{Fe}_{3} \mathrm{O}_{4}$ @$\left.\mathrm{SiO}_{2} @ \mathrm{mSiO}_{2}-\mathrm{COOH}\right)$.

\subsection{Characterizations}

Transmission electron microscopy (TEM) was performed on a JEM-2000. Scanning electron microscopy (SEM) was measured on a JSM-5600. Infrared spectroscopy was measured on a Perkin-Elmer series using the $\mathrm{KBr}$ pellet technique. The specific surface area was measured at $77 \mathrm{~K}$ using $\mathrm{N}_{2}$ adsorptiondesorption isotherms and BJH methods on a Micromeritics ASAP 2020 HD88 analyzer (USA). X-ray diffraction (XRD) was carried out using a Bruker D8 Advance X-ray diffractometer with a $\mathrm{Cu} \mathrm{K} \alpha \mathrm{X}$-ray source operating at $9 \mathrm{kV}$ and $200 \mathrm{~mA}$. Magnetization measurements of the samples were measured with a Quantum Design vibrating sample magnetometer (VSM) at room temperature in an applied magnetic field sweeping from -15 to 15 kOe. The concentrations of the heavy metal ions in the solutions were measured by atomic absorption spectroscopy.

\subsection{Regeneration studies}

For the potential practical application of the $\mathrm{Fe}_{3} \mathrm{O}_{4} @ \mathrm{SiO}_{2} @$ @$\mathrm{mSiO}_{2}-\mathrm{COOH}$ microspheres, adsorbent reusability is desirable. In this work, the used $\mathrm{Fe}_{3} \mathrm{O}_{4} @ \mathrm{SiO}_{2} @ \mathrm{mSiO}_{2}-\mathrm{COOH}$ microspheres were transferred to $1 \mathrm{M} \mathrm{HCl}$ solution and shaken by ultrasonication for $1 \mathrm{~h}$, then washed with deionized water several times in order to reuse them in the next cycle.

\section{Results and discussion}

\subsection{Controlled fabrication of multifunctional core-shell structured magnetic mesoporous silica microspheres}

The core-shell structured $\mathrm{Fe}_{3} \mathrm{O}_{4} @ \mathrm{SiO}_{2} @ \mathrm{mSiO}_{2}-\mathrm{COOH}$ microspheres can be constructed through a multistep approach (Scheme 1). First, the $\mathrm{Fe}_{3} \mathrm{O}_{4}$ microspheres are prepared via a solvothermal reaction based on the reduction of $\mathrm{Fe}(\mathrm{III})$ salts. The $\mathrm{Fe}_{3} \mathrm{O}_{4}$ microspheres have a nearly spherical shape with a mean diameter of about $350 \mathrm{~nm}$ (Fig. S1a-c, see ESI†). By using the Stöber method, a thin silica layer can coat the $\mathrm{Fe}_{3} \mathrm{O}_{4}$ microspheres to form the $\mathrm{Fe}_{3} \mathrm{O}_{4} @ \mathrm{SiO}_{2}$ microspheres (Fig. S1d$\left.\mathrm{f}^{\dagger}\right)$. The $\mathrm{SiO}_{2}$ shell can effectively prevent the chemical degradation and aggregation of the $\mathrm{Fe}_{3} \mathrm{O}_{4}$ microspheres for application in harsh liquid environments. The $\mathrm{Fe}_{3} \mathrm{O}_{4} @ \mathrm{SiO}_{2}$ microspheres still keep the spherical shape and exhibit a coreshell structure. It also can be clearly seen that the $\mathrm{Fe}_{3} \mathrm{O}_{4}$ cores are black spheres and that the $\mathrm{SiO}_{2}$ shell shows a gray color with an average thickness of about $30 \mathrm{~nm}$. The $\mathrm{Fe}_{3} \mathrm{O}_{4} @ \mathrm{SiO}_{2}$ microspheres are subsequently coated with a layer of mesoporous $\mathrm{SiO}_{2}$ through a surfactant templating approach involving the controlled hydrolysis of TEOS with CTAB as the surfactant, and then calcined in air to form the radially oriented large mesopores (Fig. S1g-i†). The $\mathrm{Fe}_{3} \mathrm{O}_{4} @ \mathrm{SiO}_{2} @ \mathrm{mSiO}_{2}$ microspheres are nearly monodispersed with a clearly distinguishable three-layer structure including an $\mathrm{Fe}_{3} \mathrm{O}_{4}$ core, a $\mathrm{SiO}_{2}$ interlayer, and a mesoporous $\mathrm{SiO}_{2}$ outerlayer with a $\sim 50 \mathrm{~nm}$ thickness. Finally, in order to introduce the carboxyl functional groups, the $\mathrm{Fe}_{3}{ }^{-}$ $\mathrm{O}_{4} @ \mathrm{SiO}_{2} @ \mathrm{mSiO}_{2}$ microspheres are first activated using APTMS, resulting in amino-functionalized $\mathrm{Fe}_{3} \mathrm{O}_{4} @ \mathrm{SiO}_{2} @$ $\mathrm{mSiO}_{2}$. Then glutaral is grafted on these amino groups and 

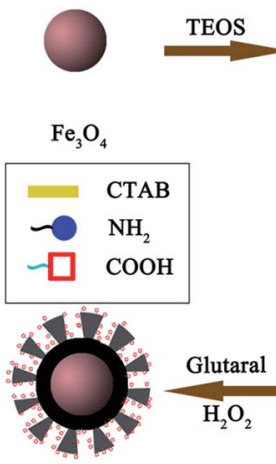

$\mathrm{Fe}_{3} \mathrm{O}_{4} @ \mathrm{SiO}_{2}$
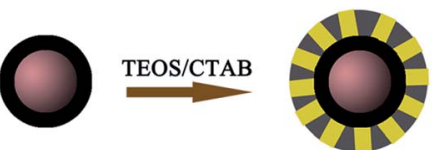

$\mathrm{Fe}_{3} \mathrm{O}_{4} @ \mathrm{SiO}_{2} @ \mathrm{SiO}_{2} / \mathrm{CTAB}$

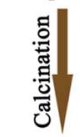

Scheme 1 Schematic illustration of the formation process of the $\mathrm{Fe}_{3} \mathrm{O}_{4} @ \mathrm{SiO}_{2} \mathrm{amSiO}_{2}-\mathrm{COOH}$ microspheres.

treated with $\mathrm{H}_{2} \mathrm{O}_{2}$ (for details, see Experimental section), through which the $\mathrm{Fe}_{3} \mathrm{O}_{4} @ \mathrm{SiO}_{2} @ \mathrm{mSiO}_{2}-\mathrm{COOH}$ microspheres are prepared (Fig. 1a). The $\mathrm{Fe}_{3} \mathrm{O}_{4} @ \mathrm{SiO}_{2} @ \mathrm{mSiO}_{2}-\mathrm{COOH}$ (Fig. 1b and c) microspheres with a mean diameter of about $510 \mathrm{~nm}$ still keep the morphological properties of the $\mathrm{Fe}_{3} \mathrm{O}_{4} @ \mathrm{SiO}_{2} @ \mathrm{mSiO}_{2}$ microspheres. It can be seen that the $\mathrm{Fe}_{3} \mathrm{O}_{4} @ \mathrm{SiO}_{2} @ \mathrm{mSiO}_{2}-$ $\mathrm{COOH}$ microspheres are well dispersed without the occurrence of aggregation and the radially oriented large mesopores are well preserved after the multistep modification, indicating the uniform properties of the sample.

FTIR spectroscopy was carried out throughout the whole surface modification process of the $\mathrm{Fe}_{3} \mathrm{O}_{4} @ \mathrm{SiO}_{2} @ \mathrm{mSiO}_{2}, \mathrm{Fe}_{3}$ $\mathrm{O}_{4} @ \mathrm{SiO}_{2} @ \mathrm{mSiO}_{2}-\mathrm{NH}_{2}$ and $\mathrm{Fe}_{3} \mathrm{O}_{4} @ \mathrm{SiO}_{2} @ \mathrm{mSiO}_{2}-\mathrm{COOH}$ microspheres (Fig. 2). All microspheres exhibit absorption bands centered around $575 \mathrm{~cm}^{-1}$ (Fe-O vibration modes), $799 \mathrm{~cm}^{-1}$ (Si-O-Si symmetric stretching), $1081 \mathrm{~cm}^{-1}$ (Si-O-Si asymmetric stretching), $1635 \mathrm{~cm}^{-1}$ (the $\delta_{\mathrm{O}-\mathrm{H}}$ of adsorbed water and $\delta_{\mathrm{N}-\mathrm{H}}$ of free or protonated amino groups), and $3400 \mathrm{~cm}^{-1}$ (O-H and $\mathrm{N}-\mathrm{H}$ stretching bands). ${ }^{16}$ Compared with the $\mathrm{Fe}_{3^{-}}$ $\mathrm{O}_{4} @ \mathrm{SiO}_{2} @ \mathrm{mSiO}_{2}$ microspheres (Fig. 2a), the absorption peak of the $\mathrm{Si}-\mathrm{OH}$ bands at $949 \mathrm{~cm}^{-1}$ in the $\mathrm{Fe}_{3} \mathrm{O}_{4} @ \mathrm{SiO}_{2} @ \mathrm{mSiO}_{2}-$ $\mathrm{NH}_{2}$ microspheres (Fig. 2b) disappeared upon functionalization, indicating that aminosilane groups are grafted on surface silanols. Moreover, two new absorption bands at $1589 \mathrm{~cm}^{-1}(\mathrm{~N}-$ $\mathrm{H}$ asymmetric stretching) and $691 \mathrm{~cm}^{-1}(\mathrm{~N}-\mathrm{H}$ symmetric stretching) can be observed, further indicating the introduction of amino groups. After the $\mathrm{Fe}_{3} \mathrm{O}_{4} @ \mathrm{SiO}_{2} @ \mathrm{mSiO}_{2}-\mathrm{NH}_{2}$

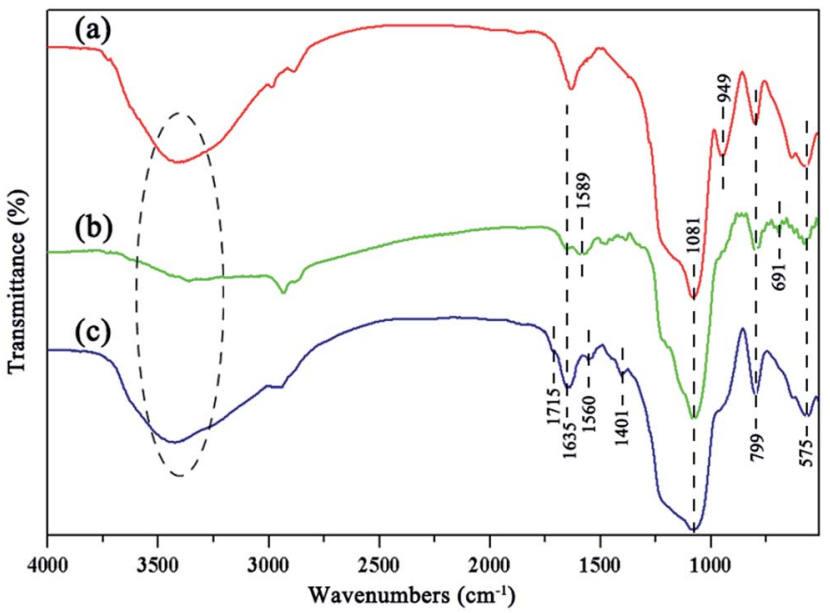

Fig. 2 FTIR spectra of the $\mathrm{Fe}_{3} \mathrm{O}_{4}\left(\mathrm{aSiO}_{2} \mathrm{amSiO}_{2}\right.$ (a), $\mathrm{Fe}_{3} \mathrm{O}_{4} \mathrm{aSiO} \mathrm{S}_{2} \mathrm{a}-$ $\mathrm{mSiO}_{2}-\mathrm{NH}_{2}$ (b), and $\mathrm{Fe}_{3} \mathrm{O}_{4} \mathrm{aSiO}_{2}\left(\mathrm{amSiO}_{2}-\mathrm{COOH}\right.$ (c) microspheres.

microspheres react with glutaral and hydrogen peroxide (Fig. 2c), the absorption bands at $1589 \mathrm{~cm}^{-1}(\mathrm{~N}-\mathrm{H}$ asymmetric stretching) and $691 \mathrm{~cm}^{-1}$ (N-H symmetric stretching) are nearly invisible, indicating new species grafting on the amino groups. The new absorption at $1715 \mathrm{~cm}^{-1}$ assigned to the $-\mathrm{COOH}$ groups is clearly visible, which suggests that the carboxylic functional groups are successfully introduced upon multi-step surface functionalization. In addition, the new bands at $1560 \mathrm{~cm}^{-1}$ and $1401 \mathrm{~cm}^{-1}$ can be attributed to the symmetric $\mathrm{COO}^{-}$vibration and to the carboxyl-carbonate structures, respectively. By reaction with $\mathrm{NaOH}$, when the $\mathrm{pH}$ is equal to 7 , the determined $\mathrm{COOH}$ loading is ca. $0.05 \mathrm{mmol} \mathrm{g}^{-1}$ for the $\mathrm{Fe}_{3} \mathrm{O}_{4} @ \mathrm{SiO}_{2} @ \mathrm{mSiO}_{2}-\mathrm{COOH}$ microspheres.

$\mathrm{N}_{2}$ adsorption-desorption measurements of the $\mathrm{Fe}_{3} \mathrm{O}_{4}$ @$\mathrm{SiO}_{2} @ \mathrm{mSiO}_{2}$ and $\mathrm{Fe}_{3} \mathrm{O}_{4} @ \mathrm{SiO}_{2} @ \mathrm{mSiO}_{2}-\mathrm{COOH}$ microspheres show type IV curves with $\mathrm{H} 1$ hysteresis loops (Fig. 3A), indicating well-uniform mesopores. In the pore size distribution curves, the samples exhibit a similar narrow pore size distribution in the range of 5-20 $\mathrm{nm}$ (Fig. 3B). The pore size, surface area and pore volumes slightly reduced after surface modification (Table 1), which can be attributed to the introduction of functional groups in the mesopores. According to previous studies, surface modification would lead to a remarkable perturbation of the pore size, surface area, and pore volume.
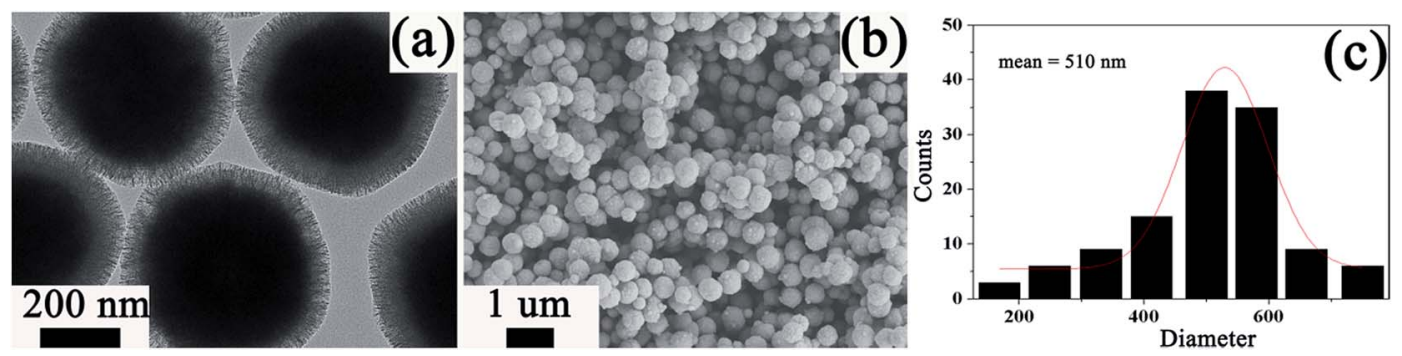

Fig. $1 \mathrm{TEM}$ and $\mathrm{SEM}$ of the $\mathrm{Fe}_{3} \mathrm{O}_{4} \mathrm{aSiO}_{2} \mathrm{amSiO}_{2}-\mathrm{COOH}$ microspheres (a and b), and size distribution histogram of the $\mathrm{Fe}_{3} \mathrm{O}_{4} \mathrm{aSiO} \mathrm{O}_{2} \mathrm{amSiO} \mathrm{O}_{2}-$ $\mathrm{COOH}$ microspheres calculated from the SEM images (c). 

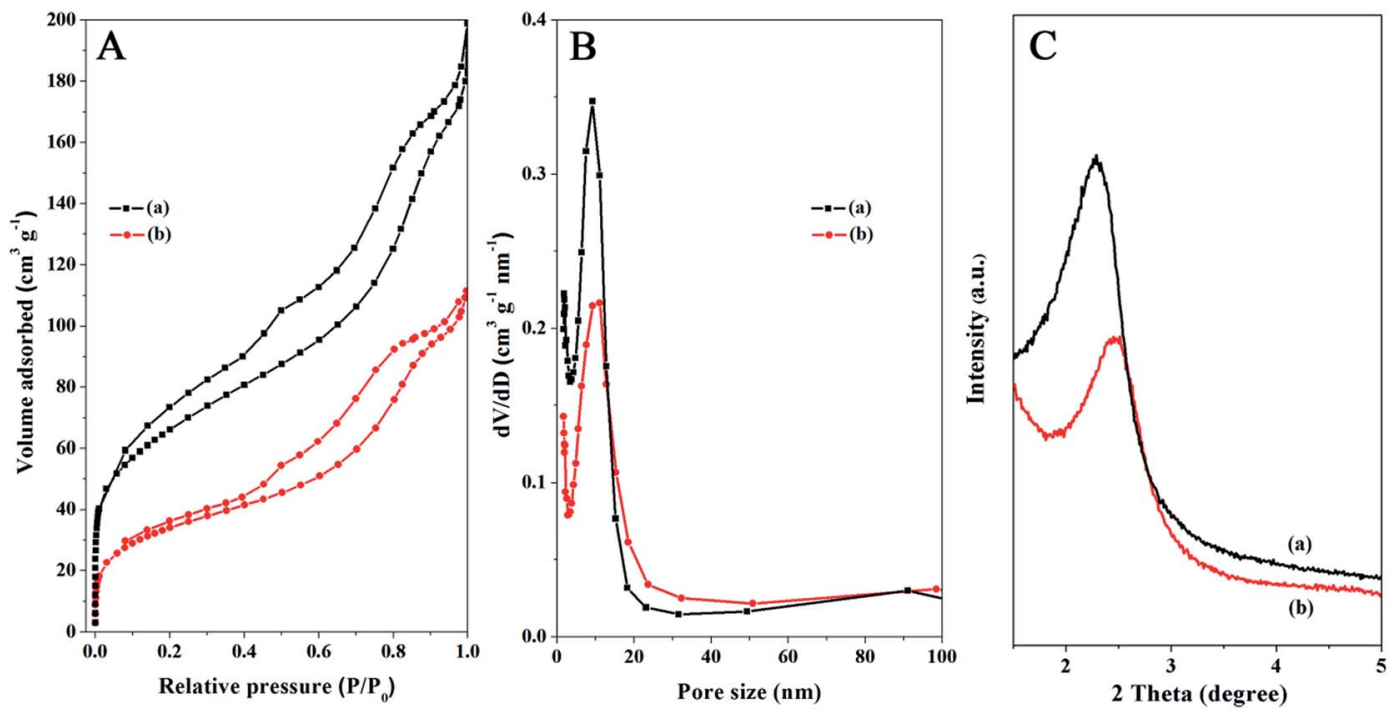

Fig. $3 \mathrm{~N}_{2}$ adsorption-desorption isotherms (A), the pore size distributions (B), and the small-angle XRD patterns (C) of the $\mathrm{Fe}_{3} \mathrm{O}_{4} @ \mathrm{aSiO}_{2} \mathrm{amSiO}_{2}$ (a) and $\mathrm{Fe}_{3} \mathrm{O}_{4} @ \mathrm{CSiO}_{2}\left(\mathrm{amSiO}_{2}-\mathrm{COOH}\right.$ (b) microspheres.

However, no such phenomenon occurred in this work, suggesting that the surface modification method adopted in this work is suitable and the highly open mesopores can be preserved. The small angle XRD patterns of the $\mathrm{Fe}_{3} \mathrm{O}_{4}$ @$\mathrm{SiO}_{2} @ \mathrm{mSiO}_{2}$ and $\mathrm{Fe}_{3} \mathrm{O}_{4} @ \mathrm{SiO}_{2} @ \mathrm{mSiO}_{2}-\mathrm{COOH}$ microspheres show a strong diffraction peak between $2 \theta=2^{\circ}$ and $3^{\circ}$, indicating an ordered mesostructure (Fig. 3C). After surface modification, the mesoporous nature is intact, which is consistent with the TEM characterization. However, a gradual decrease in the intensities and a slight shift to higher angles for the peak can be observed, suggesting that the functional groups have been grafted inside the pores, which is similar to the previous case. The wide angle XRD pattern of the $\mathrm{Fe}_{3} \mathrm{O}_{4} @ \mathrm{SiO}_{2} @ \mathrm{mSiO}_{2}{ }^{-}$ $\mathrm{COOH}$ microspheres exhibits almost the same feature as that of pure $\mathrm{Fe}_{3} \mathrm{O}_{4}$ except for a broad peak centered at $2 \theta=22^{\circ}$ (Fig. S2 $\dagger$ ), indicating that the coated $\mathrm{SiO}_{2}$ is amorphous.

The magnetic properties of the $\mathrm{Fe}_{3} \mathrm{O}_{4} @ \mathrm{SiO}_{2} @ \mathrm{mSiO}_{2}$ and $\mathrm{Fe}_{3} \mathrm{O}_{4} @ \mathrm{SiO}_{2} @ \mathrm{mSiO}_{2}-\mathrm{COOH}$ microspheres are characterized at room temperature as shown in Fig. 4. The saturation magnetizations of the $\mathrm{Fe}_{3} \mathrm{O}_{4} @ \mathrm{SiO}_{2} @ \mathrm{mSiO}_{2}$ and $\mathrm{Fe}_{3} \mathrm{O}_{4} @ \mathrm{SiO}_{2} @ \mathrm{mSiO}_{2}-$ $\mathrm{COOH}$ microspheres are 37.6 and $34.5 \mathrm{emu} \mathrm{g}^{-1}$, respectively. Although the magnetization saturation value of the $\mathrm{Fe}_{3} \mathrm{O}_{4}$ @$\mathrm{SiO}_{2} @ \mathrm{mSiO}_{2}-\mathrm{COOH}$ microspheres is lower than that of the $\mathrm{Fe}_{3} \mathrm{O}_{4} @ \mathrm{SiO}_{2} @ \mathrm{mSiO}_{2}$ microspheres due to the grafting of the carboxyl group, the $\mathrm{Fe}_{3} \mathrm{O}_{4} @ \mathrm{SiO}_{2} @ \mathrm{mSiO}_{2}-\mathrm{COOH}$ microspheres

Table 1 Textural properties of the $\mathrm{Fe}_{3} \mathrm{O}_{4} \mathrm{aSiO}_{2} \mathrm{amSiO}_{2}$ and $\mathrm{Fe}_{3}-$ $\mathrm{O}_{4} \mathrm{aSiO}_{2} \mathrm{amSiO}_{2}-\mathrm{COOH}$ microspheres

\begin{tabular}{llll}
\hline Sample & $\begin{array}{l}\text { Pore size } \\
(\mathrm{nm})\end{array}$ & $\begin{array}{l}\text { BET surface area } \\
\left(\mathrm{m}^{2} \mathrm{~g}^{-1}\right)\end{array}$ & $\begin{array}{l}\text { Pore volume } \\
\left(\mathrm{cm}^{3} \mathrm{~g}^{-1}\right)\end{array}$ \\
\hline $\mathrm{Fe}_{3} \mathrm{O}_{4} @ \mathrm{SiO}_{2} @ \mathrm{mSiO}_{2}$ & 11.08 & 193 & 0.23 \\
$\mathrm{Fe}_{3} \mathrm{O}_{4} @ \mathrm{SiO}_{2} @ \mathrm{mSiO}_{2}-$ & 11.03 & 165 & 0.17 \\
$\mathrm{COOH}$ & & &
\end{tabular}

still show strong magnetization. It can be seen that the $\mathrm{Fe}_{3}$ $\mathrm{O}_{4} @ \mathrm{SiO}_{2} @ \mathrm{mSiO}_{2}-\mathrm{COOH}$ microspheres are quickly attracted to the side of the vial with the aid of an external magnetic field, and the microspheres can redisperse well again with shaking (Fig. 4, inset).

\subsection{Adsorption behavior of the $\mathrm{Fe}_{3} \mathrm{O}_{4} @ \mathrm{SiO}_{2} @ \mathrm{mSiO}_{2}-\mathrm{COOH}$ microspheres}

Fig. 5a shows the adsorption isotherms of the heavy metal ions ( $\mathrm{Cd}(\mathrm{II}), \mathrm{Cu}(\mathrm{II})$, and $\mathrm{Pb}$ (II)) onto the prepared adsorbent $\mathrm{Fe}_{3} \mathrm{O}_{4}$ @$\mathrm{SiO}_{2} @ \mathrm{mSiO}_{2}-\mathrm{COOH}$ microspheres at room temperature, which are expressed as plots of the solid-phase pollutant concentration $v$ s. the liquid-phase pollutant concentration. It can be observed that the amount of heavy metal ions adsorbed gradually increases with the concentration of heavy metal ions. The maximum adsorption capacities for $\mathrm{Cd}(\mathrm{II}), \mathrm{Cu}$ (II), and $\mathrm{Pb}$ (II) are 395,476 , and $357 \mathrm{mg} \mathrm{g}^{-1}$, respectively. The adsorption of heavy metal ions on the $\mathrm{Fe}_{3} \mathrm{O}_{4} @ \mathrm{SiO}_{2} @ \mathrm{mSiO}_{2}-\mathrm{COOH}$ microspheres quickly reaches $88 \%, 77 \%$, and $88 \%\left(349,366\right.$ and $\left.316 \mathrm{mg} \mathrm{g}^{-1}\right)$

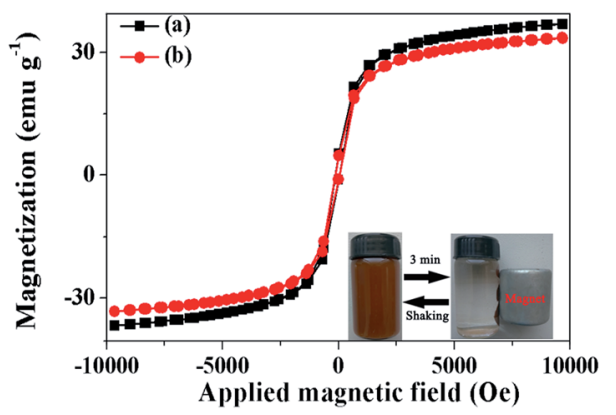

Fig. 4 Magnetic curves of the $\mathrm{Fe}_{3} \mathrm{O}_{4} \mathrm{aSiO}_{2} \mathrm{amSiO}_{2}$ (a) and the $\mathrm{Fe}_{3}-$ $\mathrm{O}_{4} \mathrm{aSiO}_{2} \mathrm{amSiO}_{2}-\mathrm{COOH}(\mathrm{b})$ microspheres, where the inset shows the separation process of the $\mathrm{Fe}_{3} \mathrm{O}_{4}\left(\mathrm{CSiO}_{2} \mathrm{amSiO}_{2}-\mathrm{COOH}\right.$ microspheres using a magnet. 

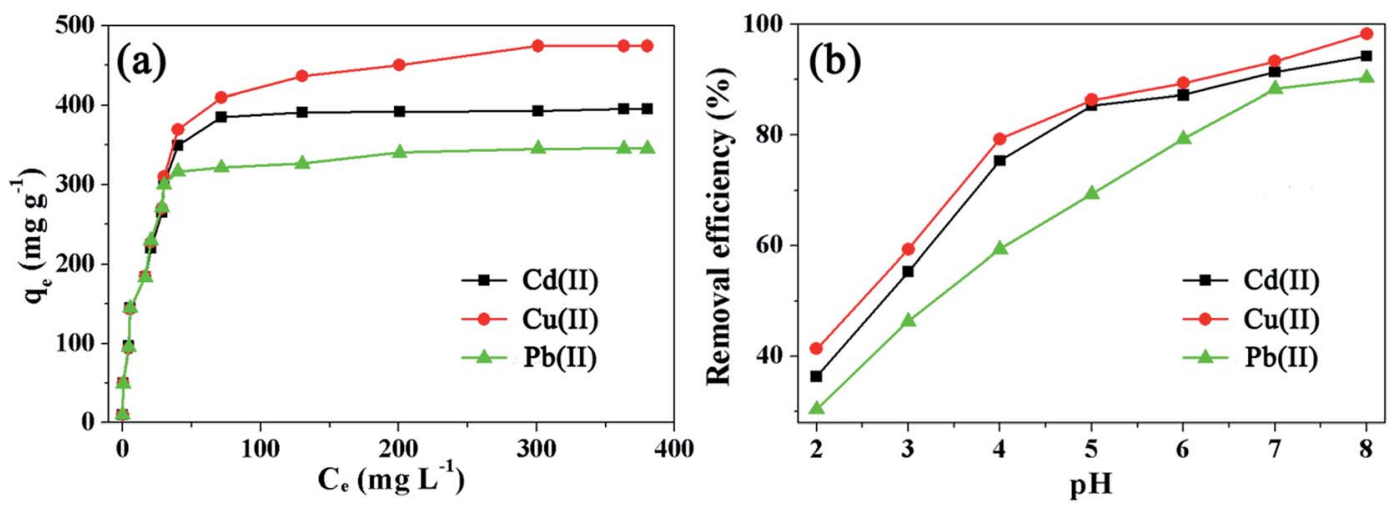

Fig. 5 Adsorption isotherms (a) and the pH effect (b) of the $\mathrm{Fe}_{3} \mathrm{O}_{4} \mathrm{aSiO}_{2} \mathrm{amSiO}_{2}-\mathrm{COOH}$ microspheres with different heavy metal ions.

of the total capacity at low concentrations below $420 \mathrm{mg} \mathrm{L}^{-1}$ for $\mathrm{Cd}(\mathrm{II}), \mathrm{Cu}$ (II), and $\mathrm{Pb}$ (II), respectively. $\mathrm{Fe}_{3} \mathrm{O}_{4} @ \mathrm{SiO}_{2} @ \mathrm{mSiO}_{2}-$ $\mathrm{COOH}$ microspheres exhibit a high adsorption capacity at low concentration, that may be derived from the complexation between the metal ions and the surface carboxyl groups.

The adsorption capacity of a given porous adsorbent strongly depends on the pore texture and surface properties. $\mathrm{Fe}_{3} \mathrm{O}_{4} @-$ $\mathrm{SiO}_{2} @ \mathrm{mSiO}_{2}-\mathrm{COOH}$ microspheres combine the highly open large mesopores and the accessible carboxyl functionalized surfaces, which lead to a high adsorption capacity compared with that of other similar magnetic adsorbents (Table S1 $\dagger$ ). However, because of the substantial increase in mass caused by the large-sized $\mathrm{Fe}_{3} \mathrm{O}_{4}$, the $\mathrm{Fe}_{3} \mathrm{O}_{4} @ \mathrm{SiO}_{2} @ \mathrm{mSiO}_{2}-\mathrm{COOH}$ microspheres show a smaller BET surface area value, thus leading to a lower adsorption capacity compared with that of some mesoporous adsorbents.

The adsorption of heavy metal ions is significantly affected by the solution $\mathrm{pH}$. As shown in Fig. $5 \mathrm{~b}$, when the $\mathrm{pH}$ increases from 2.0 to 8.0, the percentage of removed heavy metal ions ( $\mathrm{Cd}(\mathrm{II}), \mathrm{Cu}(\mathrm{II})$, and $\mathrm{Pb}$ (II)) increases gradually. The adsorption capacity of the $\mathrm{Fe}_{3} \mathrm{O}_{4} @ \mathrm{SiO}_{2} @ \mathrm{mSiO}_{2}-\mathrm{COOH}$ microspheres is strong under near-neutral and alkaline conditions while it is poor under strong acidic conditions. Under near-neutral and alkaline conditions, the negatively charged carboxylate ions exhibit a much stronger coordinative affinity towards heavy metal ions, and they can capture the target metal ions by forming chelate complexes, which leads to the high removal efficiency of $\mathrm{Cd}(\mathrm{II}), \mathrm{Cu}$ (II), and $\mathrm{Pb}$ (II).

Three adsorption models named Langmuir, Freundlich and Temkin are employed to describe the adsorption, and are presented in eqn $\mathrm{S}(2)-\mathrm{S}(4) \dagger^{21-24}$ The comparisons between the empirical adsorption isotherms and their fitting curves obtained from the above three models are shown in Fig. S3, $\dagger$ and the corresponding parameters obtained from nonlinear regression are shown in Table 2. Based on the value of the correlation coefficients $\left(R^{2}\right)$, it can be seen that the Langmuir isotherm is a more suitable isotherm for the experimental data, illustrating that the form of the heavy metal ions on the surface of the $\mathrm{Fe}_{3} \mathrm{O}_{4} @ \mathrm{SiO}_{2} @ \mathrm{mSiO}_{2}-\mathrm{COOH}$ microspheres is a monolayer adsorption and the major binding sites in the sorbent are homogeneously distributed. A high value of $K_{\mathrm{L}}$ indicates higher affinity.

The kinetics of $\mathrm{Cd}(\mathrm{II}), \mathrm{Cu}(\mathrm{II})$, and $\mathrm{Pb}$ (II) onto the $\mathrm{Fe}_{3} \mathrm{O}_{4} @$ @$\mathrm{SiO}_{2} @ \mathrm{mSiO}_{2}-\mathrm{COOH}$ microspheres are presented in Fig. 6a. It can be seen that an adsorption equilibrium is attained only within $\sim 30$ min. Notably, the adsorption of the heavy metal ions is very rapid in the first $20 \mathrm{~min}$, then the adsorption rate reduces and the adsorption amount of the heavy metal ions is almost constant from 20-30 min and gradually increases with prolonged contact time. The initial rapid adsorption within the first 20 min can be ascribed to a slight resistance for the diffusion and adsorption of the heavy metal ions into the highly open and carboxyl functionalized mesopores. After that, heavy metal ions have to traverse farther and deeper into the available adsorption sites, thus slowing down the adsorption rate from 20-30 min. The intra-particle diffusion model describes the movement of species from the bulk of the solution to the solid phase. It can be defined as follows:

$$
q_{t}=k_{\mathrm{id}} t^{1 / 2}+c
$$

Table 2 Adsorption isotherm models and corresponding parameters for the removal of $\mathrm{Cd}(\Perp), \mathrm{Cu}(\Perp)$, and $\mathrm{Pb}_{(\Perp)}$ on the $\mathrm{Fe}_{3} \mathrm{O}_{4} \mathrm{aSiO}_{2}\left(\mathrm{amSiO}{ }_{2}-\right.$ $\mathrm{COOH}$ microspheres

\begin{tabular}{|c|c|c|c|c|c|c|c|c|c|}
\hline Metal ions & \multicolumn{3}{|c|}{ Langmuir isotherm } & \multicolumn{3}{|c|}{ Freundlich isotherm } & \multicolumn{3}{|c|}{ Temkin isotherm } \\
\hline $\mathrm{Cu}(\mathrm{II})$ & 513 & 0.039 & 0.96 & 100 & 0.278 & 0.93 & 38 & 9 & 0.63 \\
\hline $\mathrm{Pb}$ (II) & 359 & 0.102 & 0.96 & 116 & 0.202 & 0.83 & 40 & 8 & 0.69 \\
\hline
\end{tabular}



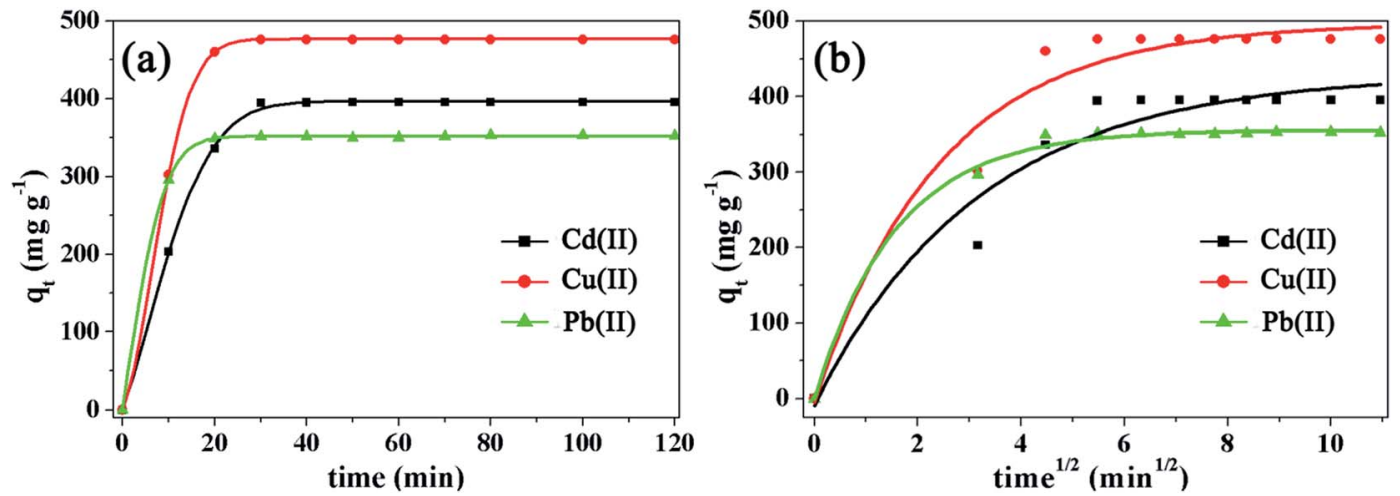

Fig. 6 Adsorption rate (a) and intra-particle diffusion model (b) of the $\mathrm{Fe}_{3} \mathrm{O}_{4}\left(\mathrm{aSiO}_{2} \mathrm{amSiO}_{2}-\mathrm{COOH}\right.$ microspheres with different heavy metal ions.

Table 3 Kinetic adsorption parameters of heavy metal ions on the $\mathrm{Fe}_{3} \mathrm{O}_{4}\left(\mathrm{CSiO}_{2}\left(\mathrm{amSiO}{ }_{2}-\mathrm{COOH}\right.\right.$ microspheres obtained using a pseudo-firstorder kinetic model and a pseudo-second-order kinetic model

\begin{tabular}{lllllll}
\hline & \multicolumn{2}{l}{ Pseudo-first-order } & & & \multicolumn{2}{c}{ Pseudo-second-order } \\
\cline { 2 - 3 } Metal ions & $k_{1}\left(\mathrm{~min}^{-1}\right)$ & $q_{\mathrm{e} 1}\left(\mathrm{mg} \mathrm{g}^{-1}\right)$ & $R^{2}$ & & $k_{2}\left(\mathrm{~min}^{-1}\right)$ & $q_{\mathrm{e} 2}\left(\mathrm{mg} \mathrm{g}^{-1}\right)$ \\
\hline $\mathrm{Cd}(\mathrm{II})$ & 69 & 370 & 457 & 0.76 & 0.12 & 445 \\
$\mathrm{Cu}(\mathrm{II})$ & 85 & 346 & 0.86 & 0.20 & 0.95 \\
$\mathrm{~Pb}(\mathrm{II})$ & 65 & & & 0.97 & 0.55 & 363
\end{tabular}

where $q_{t}$ is the amount of the adsorbates at time $t\left(\mathrm{mg} \mathrm{g}^{-1}\right), k_{\mathrm{id}}$ is the intra-particle diffusion equation constant $\left(\mathrm{mg} \mathrm{g}^{-1} \mathrm{~min}^{-1 / 2}\right)$, $c$ is the film thickness, and $t$ is the time (min). As seen in Fig. 6b, the plots of $q_{t}$ against $t^{1 / 2}$ first fit the linear behavior according to the intra-particle diffusion model, then a deviation occurs, indicating that the adsorption is at least a two-step process. The first step is controlled by the intra-particle diffusion and the second step can be ascribed to the pore diffusion.

In order to further understand the mechanisms of adsorption and the heterogeneity of the adsorbent surface, the kinetic experimental data have been evaluated using a pseudo-firstorder kinetic model and a pseudo-second-order kinetic model, ${ }^{25}$ respectively (Fig. S3 $\dagger$ ). Due to diffusion and adsorption being often experimentally inseparable, the heavy metal ion adsorption onto the $\mathrm{Fe}_{3} \mathrm{O}_{4} @ \mathrm{SiO}_{2} @ \mathrm{mSiO}_{2}-\mathrm{COOH}$ microspheres may be a complicated process that includes diffusion, coordinate bond formation and chemical reactions simultaneously. From the results obtained (Table 3 ), the value of $R^{2}$ of the pseudo-second-order model is closer to 1 compared with that of the pseudo-first-order model, suggesting that the adsorption process can be accurately described by the pseudo-second-order model, thus the adsorption of heavy metal ions onto the $\mathrm{Fe}_{3}$ $\mathrm{O}_{4} @ \mathrm{SiO}_{2} @ \mathrm{mSiO}_{2}-\mathrm{COOH}$ microspheres may take place based on a chemical process through the sharing or the exchange of electrons. Additionally, it is found that repeated washing of the used $\mathrm{Fe}_{3} \mathrm{O}_{4} @ \mathrm{SiO}_{2} @ \mathrm{mSiO}_{2}-\mathrm{COOH}$ microspheres with an acid solution and with deionized water can lead to its regeneration. Through repeated adsorption-desorption cycles as shown in Fig. 7, the adsorption efficiency decreased slightly in sequential cycles. And $\mathrm{Fe}_{3} \mathrm{O}_{4} @ \mathrm{SiO}_{2} @ \mathrm{mSiO}_{2}-\mathrm{COOH}$ still shows absorption bands at $1715 \mathrm{~cm}^{-1}, 1560 \mathrm{~cm}^{-1}$ and $1401 \mathrm{~cm}^{-1}$ in the FTIR spectrum after multiple reuses (Fig. $\mathrm{S} 4 \dagger$ ), proving the existence of the carboxylic functional groups. However, the decrease in the absorption intensity indicates the leaching of adsorption sites, thus resulting in the adsorption efficiency decreasing in sequential cycles. After multiple reuses $\mathrm{Fe}_{3} \mathrm{O}_{4} @ \mathrm{SiO}_{2} @ \mathrm{mSiO}_{2}-$ $\mathrm{COOH}$ still maintains a high adsorption capacity, and the pore size, BET surface area and pore volume structure of $\mathrm{Fe}_{3} \mathrm{O}_{4}$ @$\mathrm{SiO}_{2} @ \mathrm{mSiO}_{2}-\mathrm{COOH}$ only exhibit a slight decrease (Table $\mathrm{S} 2 \dagger$ ), suggesting the stability and reusability of the $\mathrm{Fe}_{3} \mathrm{O}_{4} @ \mathrm{SiO}_{2} @$ @$\mathrm{mSiO}_{2}-\mathrm{COOH}$ microspheres, which is owing to their unique textural structure and surface properties.

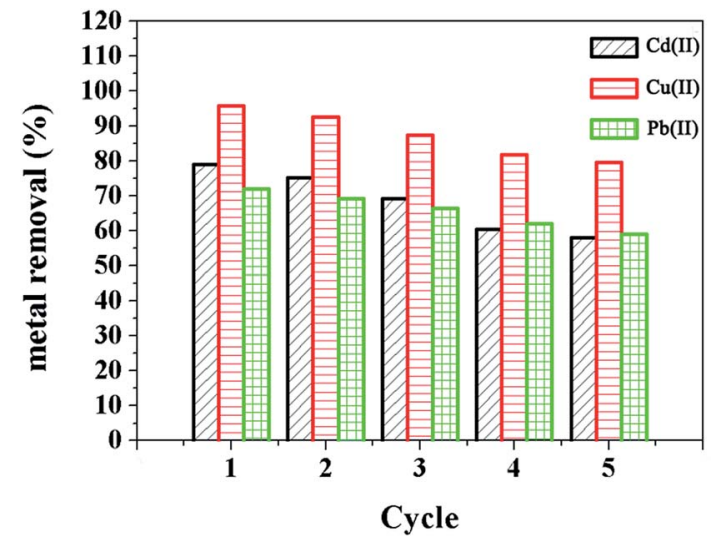

Fig. 7 Sorption-desorption cycles of the $\mathrm{Fe}_{3} \mathrm{O}_{4} \mathrm{QSiO}_{2}\left(\mathrm{amSiO}_{2}-\right.$ $\mathrm{COOH}$ microspheres with different heavy metal ions. 


\section{Conclusions}

In conclusion, we describe the synthesis of novel core-shell structured magnetic mesoporous silica microspheres combining well designed surface properties and a mesoporous structure and we also describe their enhanced adsorption performance. The obtained $\mathrm{Fe}_{3} \mathrm{O}_{4} @ \mathrm{SiO}_{2} @ \mathrm{mSiO}_{2}-\mathrm{COOH}$ microspheres possess a number of important features as a recyclable adsorbent: they contain a mesoporous $\mathrm{SiO}_{2}$ shell with radially oriented large mesopores $(11.03 \mathrm{~nm})$ and accessible carboxyl functionalized surfaces for an enhanced adsorption performance, a high field-responsive magnetic $\mathrm{Fe}_{3} \mathrm{O}_{4}$ core for efficient magnetic separation, and a $\mathrm{SiO}_{2}$ inter-layer for protecting the $\mathrm{Fe}_{3} \mathrm{O}_{4}$ core from chemical dissolution. Owing to the well-defined nanostructure and the highly integrated functions, the prepared material is very suitable as an adsorbent for the removal of heavy metal ions (Cd(II), $\mathrm{Cu}(\mathrm{II})$, and $\mathrm{Pb}(\mathrm{II})$ ), and exhibits a high adsorption capacity, a rapid adsorption rate, and an easy separation process. In addition, the adsorbent can be regenerated by acid treatment and reused in the next cycle with good stability. To get enhanced adsorption performance, this contribution takes further steps to coordinate mesoporous structures with surface properties, which could possibly inspire a lot of future research.

\section{Conflicts of interest}

There are no conflicts to declare.

\section{Acknowledgements}

This work was supported by the Jilin Province Science \& Technology Department Project (Grant no. 20150520020JH, 20160519020JH and 20170520122JH), the National Natural Science Foundation of China (Grant no. 51608050, 51601018 and 51671035), and the Science and Technology Research Project of the Education Department of Jilin Province (Grant no: 2016327).

\section{References}

1 M. M. Matlock, B. S. Howerton and D. A. Atwood, Chemical precipitation of heavy metals from acid mine drainage, Water Res., 2002, 36(19), 4757-4764.

2 S. Otsuki, T. Nonaka, N. Takashima, et al., Oxidative desulfurization of light gas oil and vacuum gas oil by oxidation and solvent extraction, Energy Fuels, 2000, 14(6), 1232-1239.

3 P. B. Hamilton, Ion exchange chromatography of amino acids. A single column, high resolving, fully automatic procedure, Anal. Chem., 1963, 35, 2055-2064.

4 S. H. Huang and D. H. Chen, Rapid removal of heavy metal cations and anions from aqueous solutions by an aminofunctionalized magnetic nano-adsorbent, J. Hazard. Mater., 2009, 163(1), 174-179.

5 Y. Gao, X. Chen, J. Zhang, et al., Chitin-Derived Mesoporous, Nitrogen-Containing Carbon for Heavy-Metal Removal and
Styrene Epoxidation, ChemPlusChem, 2015, 80(10), 15561564.

6 J. Song, H. Kong and J. Jang, Adsorption of heavy metal ions from aqueous solution by polyrhodanine-encapsulated magnetic nanoparticles, J. Colloid Interface Sci., 2011, 359(2), 505-511.

7 B. A. M. Al-Rashdi, D. J. Johnson and N. Hilal, Removal of heavy metal ions by nanofiltration, Desalination, 2013, 315, 2-17.

8 S. Babel and T. A. Kurniawan, Low-cost adsorbents for heavy metals uptake from contaminated water: a review, J. Hazard. Mater., 2003, 97(1), 219-243.

9 G. Crini, Non-conventional low-cost adsorbents for dye removal: a review, Bioresour. Technol., 2006, 97(9), 10611085.

10 M. Rafatullah, O. Sulaiman, R. Hashim, et al., Adsorption of methylene blue on low-cost adsorbents: a review, J. Hazard. Mater., 2010, 177(1), 70-80.

11 L. Mercier and T. J. Pinnavaia, Access in mesoporous materials: advantages of a uniform pore structure in the design of a heavy metal ion adsorbent for environmental remediation, Adv. Mater., 1997, 9(6), 500-503.

12 X. Feng, G. E. Fryxell, L. Q. Wang, et al., Functionalized monolayers on ordered mesoporous supports, Science, 1997, 276(5314), 923-926.

13 J. P. K. Reynhardt, Y. Yang, A. Sayari, et al., Periodic mesoporous silica-supported recyclable rhodiumcomplexed dendrimer catalysts, Chem. Mater., 2004, 16(21), 4095-4102.

14 N. Baccile and F. Babonneau, Organo-modified mesoporous silicas for organic pollutant removal in water: Solid-state NMR study of the organic/silica interactions, Microporous Mesoporous Mater., 2008, 110(2), 534-542.

$15 \mathrm{~S} . \mathrm{Wu}, \mathrm{F} . \mathrm{Li}, \mathrm{R} . \mathrm{Xu}$, et al., Synthesis of thiol-functionalized MCM-41 mesoporous silicas and its application in $\mathrm{Cu}(\mathrm{II})$, $\mathrm{Pb}(\mathrm{II}), \mathrm{Ag}(\mathrm{I})$, and $\mathrm{Cr}(\mathrm{III})$ removal, J. Nanopart. Res., 2010, 12(6), 2111-2124.

16 Q. Yuan, N. Li, Y. Chi, et al., Effect of large pore size of multifunctional mesoporous microsphere on removal of heavy metal ions, J. Hazard. Mater., 2013, 254, 157-165.

17 J. Sun, H. Zhang, R. Tian, et al., Ultrafast enzyme immobilization over large-pore nanoscale mesoporous silica particles, Chem. Commun., 2006, 12, 1322-1324.

18 J. Yang, D. Shen, Y. Wei, et al., Monodisperse core-shell structured magnetic mesoporous aluminosilicate nanospheres with large dendritic mesochannels, Nano Res., 2015, 8(8), 2503-2514.

19 H. Wang, Y. F. Yu, Q. W. Chen, et al., Carboxylfunctionalized nanoparticles with magnetic core and mesopore carbon shell as adsorbents for the removal of heavy metal ions from aqueous solution, Dalton Trans., 2011, 40(3), 559-563.

20 Y. Chi, Q. Yuan, Y. Li, et al., Synthesis of $\mathrm{Fe}_{3} \mathrm{O}_{4} @ \mathrm{SiO}_{2}-\mathrm{Ag}$ magnetic nanocomposite based on small-sized and highly dispersed silver nanoparticles for catalytic reduction of 4nitrophenol, J. Colloid Interface Sci., 2012, 383(1), 96-102. 
$21 \mathrm{~N}$. Yeddou and A. Bensmaili, Equilibrium and kinetic modelling of iron adsorption by eggshells in a batch system: effect oftemperature, Desalination, 2007, 206(1-3), 127-134.

22 A. Mittal, L. Kurup and J. Mittal, Freundlich and Langmuir adsorption isotherms and kinetics for the removal of Tartrazine from aqueous solutions using hen feathers, $J$. Hazard. Mater., 2007, 146(1), 243-248.

23 M. M. Saeed, A. Rusheed and N. Ahmed, Modeling of iron adsorption on HTTA-loaded polyurethane foam using
Freundlich, Langmuir and DR isotherm expressions, $J$. Radioanal. Nucl. Chem., 1996, 211(2), 283-292.

24 A. O. Dada, A. P. Olalekan, A. M. Olatunya, et al., Langmuir, Freundlich, Temkin and Dubinin-Radushkevich isotherms studies of equilibrium sorption of $\mathrm{Zn}^{2+}$ unto phosphoric acid modified rice husk, IOSR J. Appl. Chem., 2012, 3(1), 38-45.

25 Y. S. Ho and G. McKay, Pseudo-second order model for sorption processes, Process Biochem., 1999, 34(5), 451-465. 